\title{
Developing Talents vis-à-vis Fourth Industrial Revolution
}

\author{
Muhammad Anshari, Universiti Brunei Darussalam, Brunei \\ iD https://orcid.org/0000-0002-8160-6682 \\ Mohammad Nabil Almunawar, Universiti Brunei Darussalam, Brunei \\ Abdur Razzaq, Universitas Islam Negeri Raden Fatah Palembang, Indonesia
}

\begin{abstract}
The growing numbers of unemployment raises concerns around the world. With the arrival of the Fourth Industrial Revolution (4IR) many believed that 4IR might increase the unemployment rate by replacing the current jobs with automated machines such as robots whereas some argued that 4IR might reduce the unemployment rate by creating millions of new jobs. The paper aims to share the scenario of Industry 4.0 processes that affect future talent management, in determining which jobs will be severely affected, and that will be less affected. The talent mapping is a conceptual framework of job landscapes and the following four clusters examine job characteristics: machine-centric to human-centric, routine to complex, and optimization to identity. A qualitative method was deployed to extracts primary data from educators' perspectives in developing talents required for 4IR through Education 4.0. The adoption of Education 4.0 will be advantageous for developing talent in keeping up with the progressive and demanding talents in 4IR. The proposed model defined that clusters of machine-centric are jobs performed routinely on an application basis and usually structured and do not require any compassion or emotions. While developing talents for clusters in human-centric jobs, it may be difficult to replace humans due to complexities in the decision-making process and required compassion for task completion.
\end{abstract}

\section{KEYWORDS}

Fourth Industrial Revolution (4IR), Human Centric, Identity, Job Matrix Optimization, Machine Centric, Talent Development

\section{INTRODUCTION}

Advancement in technology has reshaped the structure of jobs affecting the workforce both positively and negatively. Previous research shows that this growing trend could reduce the unemployment rate by creating thousands or even millions of new jobs or increasing the unemployment rate by displacement of the current jobs by smart machines or robots (Balliester and Elsheikhi, 2018; Ford, 2009; Görmüs, 2019; Kergroach, 2017). While others believed that 4IR will create millions of new medium, provided the author of the original work and original publication source are properly credited. 
jobs (Ford, 2009; Görmüş, 2019; Kergroach, 2017) due to new innovation and economic growth that is supported by the advancement of technology (Ford, 2009).

Furthermore, the Fourth Industrial Revolution (4IR) describes the current trend of integrating physical technologies with concepts such as the Internet of Things (IoT), Big Data, Artificial Intelligence (AI), Robotics, 3D printing, and Cyber-Physical Systems (CPS) with the aim to reduce both job-related risks and costs especially in the manufacturing sector (Heinrich, 2019; Sumer, 2018; Anshari et al., 2017).

It is important to note that 4IR is not only limited to the manufacturing and production sector, but also other sectors including healthcare, retails, agriculture, education, etc. 4IR emerged not just due to the swift growth of technologies, but also due to the social and economic factors of a current globalized and interconnected world. The economic and social factors include Telecommuting, technologically-enabled freelance and consulting services, and people becoming used to work that are more flexible leading to interdependency in regards to work relationships.

Talent development in 4IR is important discussion highlighting issues concerning who is the talent to be developed, what competencies should be developed, who drives development, what is the appropriate pace of development and what is the architecture to support the development (Ziegler et al., 2019; Garavan, Carbery, \& Rock, 2012; Bloom, \& Sosniak, 1981).

Since there are not many studies discusses talent development in regards to 4IR, whether talent development processes should focus on the development of technical or generic competencies or both. The paper proposes a significant debating point of the conceptual model in developing talents and skills required in Industry 4.0. The aim of the paper is to propose a conceptual model of the job matrix of 4IR which has highlighted the nature and characteristics of a job and talent development.

The research distinguished the talent management should be developed into four clusters. These are combinations of human and machine interactions. Human and Human-to-Human Interaction is complex involving emotion, feelings, and compassion as human identity. It also emphasizes as nonroutinized tasks that need human interaction and task discretion is difficult to automate. As numerous routinized tasks are automated in the workplace, non-routinized tasks that need human interaction and task discretion are difficult to automate (Koleva, 2018). While Machine-to-Machine Interaction is noted as an important aspect as most production processes will highly depend on automation for the purpose of optimization, encompassing high-tech robotic machines.

\section{FOURTH INDUSTRIAL REVOLUTION}

The emergence of Fourth Industrial Revolution (4IR) will have a massive impact on any sectors as it entails the use of advanced technologies in any business processes leading to some jobs becoming extinct while at the same time triggering a type of jobs which will require a set of different skills being demanded future workforce. Industry 4.0 in relation to Internet of Things (IoT) which is the trending concept in the software engineering industries has a huge impact in our world. Industry 4.0 is the transformation on how products are produced, that is digitization of manufacturing (Adebayo et al., 2019). The transition of digitization of manufacturing is so convincing that it is called Industry 4.0 to reflect the fourth revolution that has occurred in manufacturing, from the first industrial revolution (mechanization by water and steam power) to the mass production and assembly lines using electricity in the second, the fourth industrial revolution will take what was started in the third where the computers and automation were adopted and enhanced with smart and autonomous systems (Marr, 2018). While, the data and machine learning fueled and supported it.

The industrial revolution begins with the introduction of water and steam as a source of power for machines better known as Industry 1.0, followed by industry 2.0 where the creation of mass production started with the help of electricity, and lastly followed by industry 3.0 which is the starting point for automation and computerization (Chea, Tan \& Huan, 2019; Hussin, 2018; Ilangakoon, Weerabahu 
\& Wickramarachchi, 2018). The evolution of technology is referred to as the Industrial Revolution 4.0 or the Fourth Industrial Revolution (Chea, Tan \& Huan, 2019).

It is an industrial revolution that is different at a fundamental level from the other revolution (Mikic, 2020). It entails the usage of smart technologies in manufacturing processes, platforms and practices which involve extensive machine-to-machine (M2M) and IOT leading to automation, higher levels of monitoring and communication and smart machines able to analyze and identify problems by themselves (Moore, 2019). Moore (2019) also stated that, unlike other industrial revolutions, Industry 4.0 is brought about by government entities, rather than a company that produces innovative products or services and universities of the future.

Industry 4.0 is a term that was first used in Germany at the Hanover fair in 2011 (Görmüş, 2019). It describes the current trend of integrating physical technologies with concepts such as internet of things (IoT), big data, artificial intelligence (AI), robotics and Cyber-Physical Systems (CPS) with the aim to reduce both job-related risks and costs especially in the manufacturing sector (Fomunyam, 2019, Heinrich, 2019; Sumer, 2018).

Marr (2018) sees Industry 4.0 as a change in the process of manufacturing into one that is fully digitalized. While, Mikic (2020) remarked that Industry 4.0 can be described through a fusion of physical, digital and biological world in diverse new technology which has an impact across all field of studies, economies and industries thus it has a significant effect on people work and life, altering their value system especially in regards to work and resulting in the creation of novel products, services, and works. Slusarczyk (2018) agreed with this statement, mentioning that implementing industry 4.0 4.0 will lead to the development of new business models which will affect the management process and the job market for future employees. Slursarczyk (2018) also mentions that Industry 4.0 is in all likelihood an unavoidable reality that organizations have to face in the future thus there is a need for them to embrace it as soon as possible (Ghobakhloo, 2018) so they will not be left behind.

It is important to note that Industry 4.0 is not only limited to the manufacturing sector but also other sectors such as healthcare sector and agriculture sector which are associated with the terms Education 4.0, Health 4.0 and Agriculture 4.0 respectively (Ilangakoon, Weerabahu \& Wickramarachchi, 2018; Khelassi et al., 2019). Both Health 4.0 and Agriculture 4.0 shared a similar purpose that is to monitor something in real-time online. One of the main purposes of Health 4.0 is to create a platform that can assist doctors or nurses to monitor their patients in real-time online regardless of their location whereas for Agriculture 4.0, a platform is used by farmers to monitor and track the status of farming processes also in real-time online (Ilangakoon, Weerabahu \& Wickramarachchi, 2018; Khelassi et al., 2019; Patil and Shekhawat, 2019. Rose and Chilvers (2018) mentioned several features of Agriculture 4.0 such as the use of robots to milk cows and the use of automated vehicles for weed identification. The benefits of Health 4.0 include efficiency and more personalized healthcare whereas the benefits of Agriculture 4.0 include the production of high-quality farm products as well as the reduction in production input (Ilangakoon, Weerabahu \& Wickramarachchi, 2018; Rose \& Chilvers, 2018).

The major challenge of 4IR as stated by Alcacer and Cruz-Machado (2019) is in trying to increase the flexibility and collaboration of production systems as technology cannot be implemented individually as its effect will be lower, rather it is only by implementing them together, new possibilities will arise that could be beneficial for the future of the company. Ghobakhloo (2019) also mentioned that there are a lot of obstacles in transitioning to industry 4.0 such as "financial capability, security issues, maintaining the integrity of the production process, IT maturity and knowledge competencies" thus industry 4.0 required companies to design a thorough strategy for transitioning into Industry 4.0 and maturity to accept an upcoming change that would occur due to Industry 4.0. In ASEAN, Mikic (2020) mentions that unprepared for Industry 4.0 due to several problems which include 1) employees unaware of benefits and opportunities that could be gained through maintaining or gaining new skills, 2) limited financial capability restricts investment that could be spent for training workers and adopting new technologies, 3) Absence of lifelong learning model that is effective and allow measurement of its effectiveness, 4) ASEAN education curriculum has not been updated to keep up 
with newer skills demands, 5) social protection correlates to jobs rather than individuals and lastly 6) social benefits are given to groups that do not participate in the workforce.

\section{OPTIMIZATION}

According to Mikic (2020) Industry 4.0 is possible due to the technologies known as Frontier Technologies which include Artificial Intelligence (AI), IoT, automation, Augmented Reality (AR), autonomous vehicles, robots, cloud computing, robotics, and others. Hawksworth (2020) mentioned the term 'Income Effect' which is closely related to the idea given by Ford (2009). Income Effect happens when a firm gains more income and consumers save more money due to the usage of robots or AI, and as a result, their spending power increases (Hawksworth, 2020; Lambert, Mulherin, Skelton $\&$ Thomas, 2020). The increase in spending power tempted them to spend their money on several other goods and services, indirectly creating more jobs (Hawksworth, 2020; Lambert, Mulherin, Skelton \& Thomas, 2020). According to Moore (2019) the benefit of Industry 4.0 is the optimization of a business process that can improve productivity and decrease inefficiency all around. Esmaeilian, Behdad and Wang (2016) also supported that the use of industrial robots and automated machines offered many benefits such as increased efficiency, better quality products, highly reliable, decreased waste and effective space usage as they will take less space than cramming 100 people to work on a production line.

It creates a real-time response that is possible due to the development of technology rather than one caused by "new form of technology" or new "business ideal" as the case had been for the previous industrial revolution. It is the digitalization of all business processes, from manufacturing to a transaction (Moore, 2019; Demartini and Benussi, 2017). Thus, the actual strength of Industry 4.0 is according to Marr (2018), the interconnectedness of machines that can communicate and exchange information digitally with each other which makes them smarter in terms of decision making due to the huge influx of data they share.

\section{NEW JOBS CREATIONS AND DEVELOPING TALENTS}

Other researches supported that Industry 4.0 will increase the unemployment rate by replacing the current jobs with automated machines such as robots (Balliester and Elsheikhi, 2018; Frey \& Osborne, 2017; Görmüş, 2019). According to Balliester and Elsheikhi (2018) job losses will be more likely to be experienced by workers who are doing routine jobs such as factory workers, bookkeepers, and product testers. In addition, traditional jobs such as banking and accountancy that can normally be found in the financial sector could be replaced by advanced technology such as Blockchain technology (Balliester and Elsheikhi, 2018). In terms of education level, örmüş (2019) predicted that workers with primary education or lower are at higher risks of getting replaced by robots whereas those who have a doctorate degree or higher are at a lower risk of getting replaced. In addition, Frey and Osborne (2017) predicted that $47 \%$ of employment in the US are at high risk of getting replaced by automated machines. Marr (2018) also stated that it is a revolution that entails machines being able to communicate with other machines autonomously without any human agent involved. Types of jobs that are routine tasks require structured decision making and physically demanding jobs will be eliminated as a consequence of Industry 4.0 (Alcacer \& Cruz-Machado, 2019). Ghobakhloo (2018) also states that there are many merits that could be gained which override any potential costs needed in moving towards industry 4.0, especially for high-level global manufacturers that have expenses needed to invest in the new technologies.

While for new job creation, other researches stated that 4IR reduces the unemployment rate by creating millions of new jobs (Ford, 2009; Görmüş, 2019; Kergroach, 2017). Even though millions of jobs are getting removed, completely new jobs will be created due to new innovation and economic growth that is supported by the advancement of technology (Ford, 2009). New jobs that will be created 
by Industry 4.0 will most likely require the individuals to be good in information-technology (IT) skill, creativity skill, thinking-skill, complex-problem skill, decision-making skill, communication skill, and most importantly human skills especially if the jobs involve human-relations or customer services (Görmüş, 2019; Hussin, 2018; Kergroach, 2017; World Economic Forum, 2018). Therefore it is important for the education system to hone the aforementioned skills, especially the Millennials Generation for Industry 4.0 namely Education 4.0.

Since, developing talents in the knowledge economy, characterized by complex and dynamic competitive environments, knowledge-based resources represent the true source of sustained competitive advantage for any organizations (de Pablos, 2002, 2003). Education 4.0 is often connected to smart learning. According to Zhuang et. al (2017:4), smart learning environments are based on Information Communication Technology (ICT) that are centered on learners who can use the eco-system and adopt learning styles as well as learning abilities. Furthermore, smart learning environments are high levels of digital environment that are considered convenient, engaging and results in effective learning. Simply put, it is a learning environment that can be accessed at any time, in any way and with any pace.

\section{HUMAN-MACHINE INTERACTIONS}

In the 4IR is also the era of Cyber-Physical Systems (CPS) that comprises of smart machines, storage systems, and production facilities. CPS comprises interactions between Machine to Machine (M2M) and Human to Machine (H2M). M2M refers to any technology that enables networked devices to exchange information and perform actions without the manual assistance of humans (Rouse, 2017). Both Artificial Intelligence (AI) and Machine Learning (ML) facilitate communication between systems, allowing them to make autonomous choices. The main components of an M2M system include a Wi-Fi or cellular network, RFID, sensors, and software program to help a network device interpret data and make decisions (Rouse, 2017). M2M is applied to many different sectors of the industry such as manufacturing, remote monitoring, utilities, telemedicine, robotics, automotive industry, logistics and fleet management, traffic control, security and many more. The future of M2M is through the combination of Internet of Things (IoT) which optimizes M2M system into one large, connected ecosystem (Rouse, 2017). The integration of M2M and IoT has brought a transformation in improving mobile payment processes and creating new opportunities for different purchasing behaviors. Smart home systems have also begun to incorporate new M2M technology. The use of M2M in this embedded system enables home appliances and other technologies to have real-time control of operations as well as the ability to remotely communicate.

Human to Machine (H2M) is the interaction and communication between human users and machines in an environment involving several interfaces. In the context of industry 4.0, human to machine interaction include big data analytics, robot-assisted production, self-driving logistics vehicles, augmented reality and additive manufacturing (Nardo et al., 2020). For big data and analytics, companies will utilize algorithms in order to analyses real-time data. While the use of big data involves a reduction of a number of workers, there will be more job opportunities created, such as an industrial data scientist who has skills to use statistical programming languages (The evolution of man-machine interaction: the role of a human in Industry 4.0 paradigm, 2020). The difference between traditional workers and workers of industry 4.0 is the competence and knowledge gap. Robot-assisted production in industry 4.0 will decrease manual labor in production. The introduction of robot will transform the workplace in production as there will be less physical effort for the worker since most, if not all, routine jobs will be done by machines. Therefore, creating the role of robot coordinator, who will supervise robots on the floor and respond to any malfunctions or machine errors (The evolution of man-machine interaction: the role of a human in Industry 4.0 paradigm, 2020). Essentially, the robot coordinator will carry out both routine and emergency maintenance tasks to ensure a smooth workflow. The use of automation to assist employees will be particularly beneficial in many developed countries. 
Machines will allow workers to do their job easier while significantly reducing any potential errors and workplace accidents. Robots, smart machines, and other smart products that communicate with one another to make autonomous decisions will facilitate this flexible process (Nardo et al., 2020).

Opportunities that are being brought forward by IR4 would be a better-quality lifestyle from the technology, new products, and markets, enhanced health services leading to longevity (Diwan, 2017). It is an ongoing process that continues on the progress and development from the third industrial revolution. This era focuses on wireless connectivity and sensors that are connected to a system that can monitors a whole line of products and does decision making on its own without human assistance therefore, smart factories.

\section{METHODS}

To achieve this paper's objective as mentioned in the introduction section, a qualitative method was deployed as the most appropriate methodological approach to identify and evaluate the key points of the topic. Firstly, search engines such as Google, Google Scholars, Emerald Insights, Researchgate, and Elsevier were comprehensively used to search the keywords that comprise o 'Industrial Revolution 4.0', 'Fourth Industrial Revolution AND Employment, 'Cyber-Physical Systems AND Industry 4.0' and workforce AND employment demand'. Moreover, multiple systematic literature reviews and research papers revolving around the aforementioned keywords were used extensively to construct a basic understanding of this paper's topic. Articles and research papers in English language were used in this paper. Secondary data from previous research papers and reports from recent years (ranging from 2014 to 2019) were used to gain insights into 4IR and workforce issues. The concept that arises in the Job Matrix of 4IR was derived from systematic analysis and synthesis of the interaction between humans and machines in the context of 4IR. Secondly, empirical work was conducted through interview sessions with parents and educators in views of developing talents and skills for facing Industrial Revolution 4.0.

\section{Cyber Physical Systems (CPS)}

With the autonomous exchange of information and independent of control, these are possible with the activities of IoT (Industrial Internet of Things) consisting of numerous sensors performing in real-time and exchanging data at the same time into a local or cloud server. An example of industry 4.0's application in the medical world is surgery made possible by doctors remotely from far away hence the term 'smart surgeon'. Basically, doctors use control to the robots with strong connection and bandwidth to execute real-time surgery (Eveleth, 2014). As the IR4 focuses on stronger connectivity and uninterrupted data exchange, China is now leading with the 5G development that can possibly affect strongly on our daily lives such as the Internet of Things (IoT) (Liu, Shi, Wang \& Li, 2017).

Figure 1 shows a simple scenario of CPS in Industry 4.0. Customers may order products from any digital platform. They pay using digital wallets or any Financial Technology (FinTech) services. Once a business receives the payment from customers, the manufacturing processes start a production. Smart Factory 1, 2, 3, etc. refer to the process of one factory communicates with other factories for production purpose and optimization. The process of communication one factory with others is automated with no human intervention. For instance, let say customers order two thousand shoes. While the capacity for production in one factory is only one thousand shoes. Then the first factory will communicate with the next factories to produce another one thousand shoes. The smart factory may also be attributed to a dark factory by referring to the process of production that is no required any lighting. Unlike human workers in a factory who need lighting for production, machines do not require any lighting so that smart factories can be energy saving. Those processes form ordering products up to the delivery by using an autonomous vehicle or drone are done with very little human intervention. Industry 4.0 in this scenario is powered by Big Data, Expert Systems, Internet of Things, AI, Sensor, Cloud Computing, etc (Anshari, 2020). The idea of CPS in Industry 4.0 is for optimization. Before 
Figure 1. Cyber Physical Systems (CPS) in Industry 4.0 (Source: Author's Compilation, 2020)

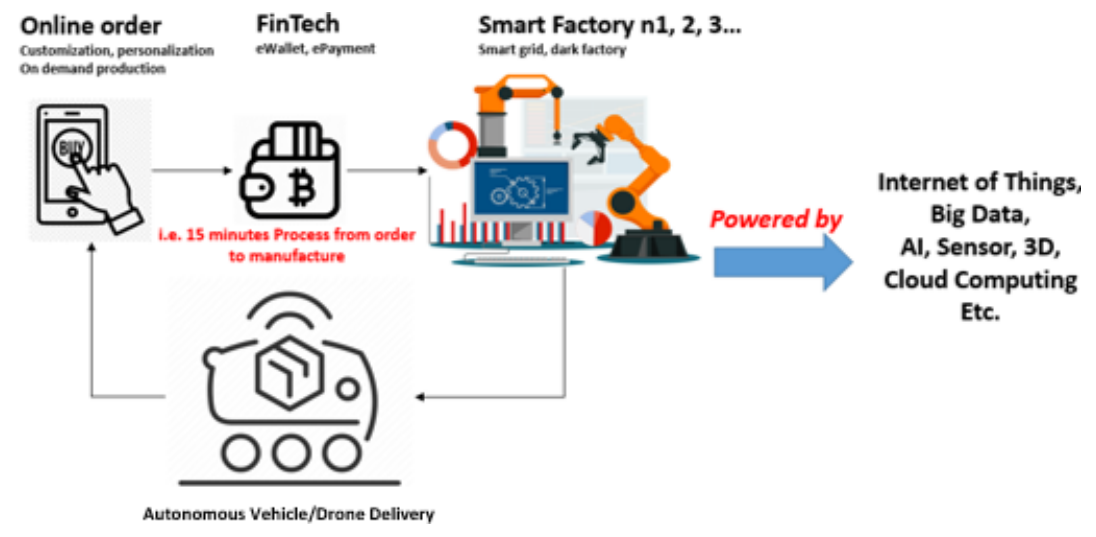

it could take a month for ordering products to final delivery to customers. In Industry 4.0 as shown in Figure 1, processes could take a much shorter time with fewer human interactions. It is obvious the challenges from Industry 4.0 will affect the availability of human workforces. Next, it discusses the proposed Job Matrix model to portray the classification of jobs in 4IR.

\section{Job Matrix in 4IR}

There are various types of jobs that can be classified into these 4 clusters shown in Figure 2 which are the Machine-to-Machine interaction (cluster 1), Human-to-Machine interaction (cluster 2), Human-toHuman Interaction with Complex and Creativity (cluster 3) and Human-to-human Interaction Routine (cluster 4). It shows that different types of jobs can be found in each cluster that either requires a human, machine or both interaction.

It is essential to define the keyword found on the arrows for further understanding which are human-centric (identity), machine-centric (optimization), routine and complex. In my opinion, human-centric are those jobs that still require humans' knowledge and skills in performing their job such as problem-solving and decision making. Machine centric are those that are programmed

Figure 2. Job Matrix in 4IR (Source: Author's Compilation, 2020)

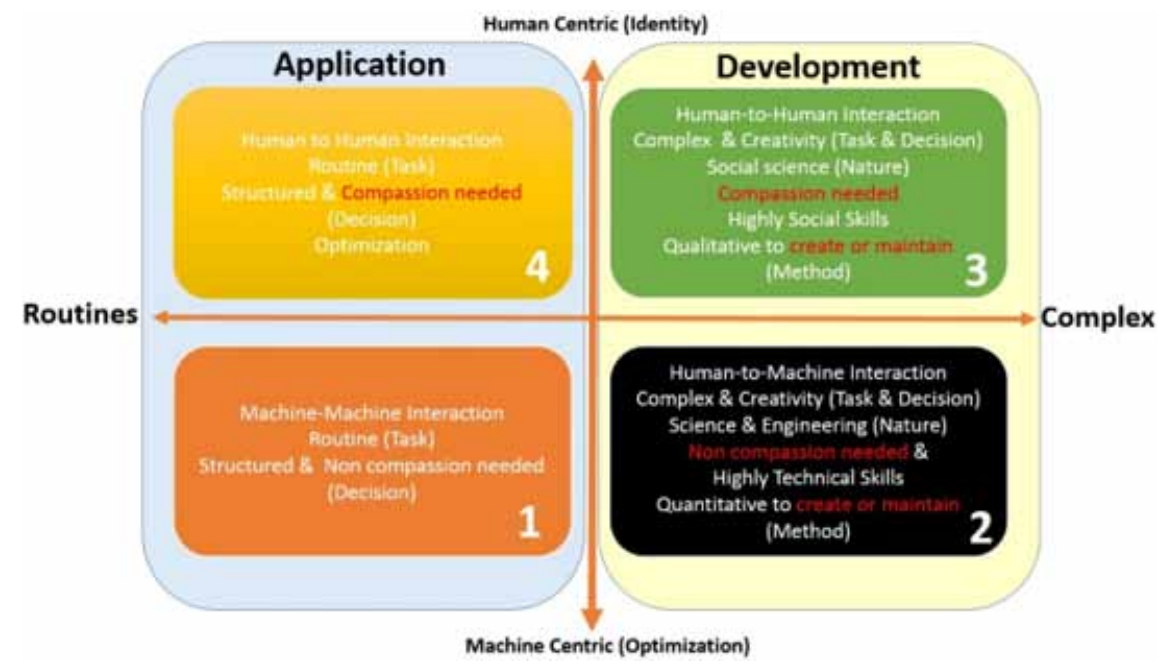


by a human to perform the fixed task assigned to a machine in the automation process without the need for human observing all the time. According to Cambridge Dictionary (n.d.), routine refers to a set of activities or jobs that are performed daily. As for a complex, it is defined as having multiple networks that linked together closely or complicatedly ("Meaning of complex in English," n.d.). It is also the classification of human-centric jobs and machine-centric jobs. Towards the $\mathrm{x}$-axis shows the complexity of specific jobs while the y-axis shows the machine the centric job to a more humancentric job. The more complex/difficult the job is shown in the y-axis towards human-centric, the more it needs human intervention to accomplish decision-making. Therefore, the conceptual framework is very imperative for workforce mapping especially in optimizing identity or identifications. When job landscapes are compartmentalized and can be easily identified, one can single out which job landscapes that can be maintained, replaced, or/and are potential in creating more job opportunities.

\section{Cluster 1 - Machine to Machine Interaction}

Jobs in these clusters consist of tasks that are routine and structured with less compassion needed in decision-making. According to Booysen, et. al (2012:530), when two (2) electronic systems communicate, without any human intervention, it is a process that is called Machine to Machine (M2M) interaction. Its goals are to share information between electronic systems autonomously and are operated using both wired and wireless communication. Cluster 1 shows machine-centric with routine works. For these job characteristics, it suggested that task which is routine and does not need human inputs such as compassion can be replaced by machinery through machine and machine interaction. By having a routine task, the flow can be structured accordingly, and human intervention is less of a factor. This is where the ability of a physical system to make decisions on their own and perform tasks autonomously as possible. In another word, decentralized the decision. In this cluster, it is about networking devices with machines to do the routine task. For example, product restocking, the vending machine can notify the distributor to refill when detected a particular item is running low. Another job that may be replaced by machine are warehouse management systems and supply chain management as those advanced technologies or applications can help to track and monitor the items without human guidance (Rouse, 2019). Those jobs that are in cluster 1 will be replaced by a machine such as security guard, accountant, truck driver, farmer, construction worker, front desk jobs.

\section{Cluster 2 - Human to Machine Interaction}

The second cluster is machine-centric with complex works. Human to Machine needs high technical skills and as of now; it is complex to create and maintain. For this job matrix, it is where a machine needs human interaction to solve complex works with their creativity. This is where human interaction (highly skilled workers) is needed in handling machines with less compassion needed because of human and machine interactivity. Jobs in this cluster are complex and require creativity to execute tasks and also decision-making. There are garnered more to the Science and Engineering fields which require high technical skills. These types of jobs are more related to those who have the know-how skills by incorporating them into/with digital technologies. For example, when surgeons use artificial intelligence (AI) to perform surgery (also known as robotic surgery), in which their expertise is "built through frequent exposure and training" (Sujan et. al, 2019:3). In healthcare, it is not easy for the AI algorithms to replace human-patient interactions as well as situation awareness. Therefore, jobs in this cluster need frequent training developed from high technical skills. This is similar to the generation of self-driving cars which is adopted by Uber. Ever since Uber's self-driving car killed a pedestrian in 2018, Uber is now operating their self-driving cars with safety drivers behind the wheel during daylight hours (Shepardson, 2020). Human to Machine interaction is used in the aftermath of the crash, in which Uber has upgraded new technologies to have more safety precautions in autonomous vehicles. Examples of the job found in this cluster are those engineers, technicians, scientists, air-traffic control, computer programming, software developer and trainers in teaching those technologies and AI. 


\section{Cluster 3 - Complex Human to Human Interaction}

Cluster 3 are those jobs that require human to human interaction for a development basis. The jobs found in this cluster requires a human's creativity and complex in performing a task and making a decision. Human feelings and emotions (compassion) are needed in this cluster. It also requires high social skills in creating or maintaining human relationships. The jobs also allow a human to gain or share knowledge thus creating or forming tacit and explicit knowledge. For this cluster, the job landscape thrives on complexity in decision-making, creativity as well as innovation. But unlike cluster 3 , this cluster offers job landscapes that have high social skills and compassion. This cluster, therefore, is made up of people who work closely with society and people in general. It is human-centric with complex tasks. In this matrix, human to human interaction is needed where it requires highly social skills, compassion and qualitative. An example of jobs under this matrix is doctors where it needs their skills including their social skills when treating patients. Other jobs included under this matrix are lawmakers, politicians, and diplomats.

Human to Human (H2M) is more complex as it is to think of the development, and creativity is needed to make a decision. Everyone in this cluster must have social sciences, openness to accept judgments and they must have high skills of communication. Everyone in this cluster must have compassion, by understand someone's needs, strengths, and weaknesses. To maintain this H2M, a person must be conditional to everyone. For instance, this is the top leaders/managers in an organization where they are from different managements but share the same goal. Everyone has their own problem in the management of how things work, such as marketing or human resource. Therefore, they must understand within each other, give and take to have a win-win solution.

Furthermore, they are also those who are in healthcare practitioners or people who work best as mediators in a crisis situation. For example, doctors and midwives. This cluster can also include community support groups such as mental health support groups. For instance, during this delicate time of Covid-19. Mental health support groups are very much needed as in times of crisis, different people react to situations differently. Some may have more fear and anxiety than others. Some are just lonely and have no family support. Therefore, strong mental health support to lessen any possible post-traumatic-stress-disorder (PTSD). In addition, other examples of the job found here are managers, advice workers, counselors, social workers, police officers, local government career, human resources officer and volunteer coordinators.

\section{Cluster 4 - Routine Human to Human Interaction}

Cluster 4 is those jobs that also require human to human interaction but for application and routine basis. The jobs in these clusters are mostly structured so the activities of the works are the same and are fixed daily. It also requires feelings or emotions of humans when conducting their job as the tasks may require decision making in order to have their job done effectively and in the best manner. This can also build up a relationship between humans. In this cluster, the nature of the job landscapes is 'service providers.' Therefore, they cannot be replaced by machines because services rendered are dependable on human interaction and skills. The arc of cluster 4 is routine tasks as well as optimization. As far as optimization is concerned, they need digital technologies incorporated in their job landscapes. This type of interaction can also be seen in jobs such as tour operators or tour guides. In the past, these job designations didn't need digital technologies as they are mostly operated by those who have exceptional social skills; ones who are articulate and adventurous. But today, having those qualities alone are not enough. New technologies must be incorporated as well. Some examples of the job found in this cluster are event planners, proofreader, tour guides, and elderly caregivers.

For example, business startups set up by young people that offer consultations or services by incorporating technologies. BD Guide is an example of a business start-up that encourages domestic tourism to anyone who wishes to explore Bandar Seri Begawan. To get more information and familiarize themselves with their services, there is a BDGuide app that can be scanned via QR codes for people to access. 


\section{Developing Talents and Skills in 4IR}

Industry 4.0 is the rapid development of talents and skills prior to the changing landscape of educational technology with the new model of education. Thus, Industry 4.0 is a crucial stage that led to the advancement of Education 4.0. Education 4.0 is a retaliation to the needs of Industry 4.0 where the alignment of people and technology have created new possibilities. Education 4.0 helps a learner to further understand the learning contexts effectively compared to practicing those traditional approaches. Therefore, every educator needs to change a step forward in making this positive since the students are more fond of using technology (Lawrence, Fung Ching, Abdullah, 2019).

Education 4.0 is a new method of learning whilst compromising the use of 4IR combine education 4.0 with the use of smart technology, artificial intelligence and robotics. By integrating the use of these technologies into learning, this will help to further ease the knowledge sharing especially in a classroom setting. According to (Stein-Penn, 2020) the COVID-19 virus has caused multiple schools and college campuses to close down globally. In aligning the developing talents, Education 4.0 by the means of technology as part of the curriculum, changes in learning approach, and utilization of technology to better improve the education quality of an institution (QS, 2020). A need to adapt to the education 4.0 due to the need for self-care and personal distancing from one another during the current pandemic. Various technological barriers are faced by the people, especially by families with inadequate knowledge, as well as necessities to adopt Education 4.0. Basically, the roadmap for Education 4.0 is not always about how sophisticated the technologies are but more to how learners can utilize the technologies. For instance, during this Covid 19 period, learners are urged to use e-learning as medium of studying.

Some major challenges in developing talents and skills were identified as relativity to the online learning process. Especially from the perspectives of parents that along the process of setting up the online learning parents need to be well-prepared in ensuring the facilitation of the students is fully accommodated, especially for the primary and secondary school students that are still dependent on their parents in terms of living and expenses. The problem rises for low-income families and has more than one child as they need to spend extra budgeting for a laptop and internet connection. Nevertheless, working parents undergo the same issues and challenges in supervising and monitoring their children due to their task commitment.

For students who do not own the Wi-Fi or internet access at home will have connectivity problems to keep updated with their studies or else might need to spend the extra budget on setting up the internet access or using mobile data. Meanwhile, in regard to the educators, the issues and challenges are more likely on how to ensure all the students have full access to online learning and not missing out on any single thing of their studies syllabus content.

\section{CONCLUSION}

In conclusion, technology in developing talents and skills have their own strengths and weaknesses, but proper implementation might help keep the drawbacks to a minimum. Better planning is necessary by the government and policymakers. In developing talents for Industry 4.0, Education 4.0 needs to combine the workforce and machines to pursue new possibilities and opportunities. It will unleash the potential of digital technology, open-sourced content, and customized data of this worldly and globally linked and tech-driven world. The proposed model is expected to help in building build a blueprint for Education 4.0 that the learning from school based learning to remote and personalized learning. Furthermore, the massive usage of online learning due to the outbreak of COVID-19 will lead to the transformation of Education 4.0 as it is the beginning factor that contributes to the development of talents and skills in the Fourth Industrial Revolution. 


\section{REFERENCES}

Adebayo, A. O., Chaubey, M. S., \& Numbu, L. P. (2019). Industry 4.0: The Fourth Industrial Revolution And How It Relates To The Application Of Internet Of Things (IoT). Journal of Multidisciplinary Engineering Science Studies, 5(2).

Alcacer, V., \& Cruz-Machado, V. (2019). Scanning the Industry 4.0: A Literature Review on Technologies for Manufacturing Systems. Engineering Science and Technology, an International Journal, 22(3), 899-919.

Anshari, M. (2020, March). Workforce Mapping of Fourth Industrial Revolution: Optimization to Identity. Journal of Physics: Conference Series, 1477, 072023. doi:10.1088/1742-6596/1477/7/072023

Anshari, M., Almunawar, M.N., \& Shahrill, M. (2017). Education Info Technology. 10.1007/s10639-017-9572-7

Balliester, T., \& Elsheikhi, A. (2018). The future of work a literature review. Academic Press.

Benesova, A., \& Tupa, J. (2017). Requirements for Education and Qualification of People in Industry 4.0. Procedia Manufacturing, 11, 2195-2202. doi:10.1016/j.promfg.2017.07.366

Bloom, B. S., \& Sosniak, L. A. (1981). Talent development vs. schooling. Educational Leadership, 39(2), 86-94.

Booysen, M. J., Gilmore, J. S., Zeadally, S., \& Van Rooyen, G. J. (2012). Machine-to-machine (M2M) communications in vehicular networks. Academic Press.

Chea, C. C., Tan, J., \& Huan, J. (2019). Higher education 4.0: The possibilities and challenges. Journal of Social Sciences and Humanities, 5(2), 81-85.

de Pablos, P. O. (2002). Evidence of intellectual capital measurement from Asia, Europe and the Middle East. Journal of Intellectual Capital.

de Pablos, P. O. (2003). Intellectual capital reporting in Spain: A comparative view. Journal of Intellectual Capital.

Demartini, C., \& Benussi, L. (2017). Do Web 4.0 and Industry 4.0 Imply Education X.0? IT Pro. Retrieved from https://ieeexplore.iee.org/stamp/stamp.jsp?arnumber=7945196

Diwan, P. (2017). Is Education 4.0 an imperative for success of 4th Industrial Revolution? Retrieved from https:// medium.com/@ pdiwan/is-education-4-0-an-imperative-forsuccess-of-4th-industrial-revolution-50c31451e8a4

Esmaeilian, B., Behdad, S., \& Wang, B. (2016). The evolution and future of manufacturing: A review. Journal of Manufacturing Systems, 39(1), 79-100. doi:10.1016/j.jmsy.2016.03.001

Eveleth, R. (2014). The surgeon who operates from 400km away. Retrieved from https://www.bbc.com/future/ article/20140516-i-operate-on-people-400km-away

Fomunyam, K. G. (2019). Education and the fourth industrial revolution: Challenges and possibilities for engineering education. Academic Press.

Ford, M. (2009). The lights in the tunnel. Acculant.

Garavan, T. N., Carbery, R., \& Rock, A. (2012). Mapping talent development: Definition, scope and architecture. European Journal of Training and Development, 36(1), 5-24. doi:10.1108/03090591211192601

Ghobakhloo, M. (2018). The future of manufacturing industry: A strategic roadmap toward Industry 4.0. Journal of Manufacturing Technology Management, 29(6), 910-936. doi:10.1108/JMTM-02-2018-0057

Görmüş, A. (2019). Future of work with the Industry 4.0. Academic Press.

Hawksworth, J. (2020). AI and robots could create as many jobs as they displace. Retrieved 20 February 2020, from https://www.weforum.org/agenda/2018/09/ai-and-robots-could-create-asmany-jobs-as-they-displace/

Heinrich, M. (2019). Industry 4.0: How it will affect employment and what skills will be required to match the requirements of the market. Academic Press.

Hussin, A. (2018). Education 4.0 Made Simple: Ideas For Teaching. Academic Press. 
Ilangakoon, T., Weerabahu, S., \& Wickramarachchi, R. (2018). Combining Industry 4.0 with Lean Healthcare to Optimize Operational Performance of Sri Lankan Healthcare Industry. 2018 International Conference On Production And Operations Management Society (POMS). doi:10.1109/POMS.2018.8629460

Kergroach, S. (2017). Industry 4.0: New Challenges and Opportunities for the Labour Market. Foresight And STI Governance, 11(4), 6-8. doi:10.17323/2500-2597.2017.4.6.8

Khelassi, A., Estrela, V., Monteiro, A., França, R., Iano, Y., \& Razmjooy, N. (2019). Health 4.0: Applications, Management, Technologies and Review. Medical Technologies Journal, 2(4), 262-276. doi:10.26415/2572004X-vol2iss4p262-276

Lambert, J., Mulheirn, I., Skelton, B., \& Thomas, R. (2020). The AI Paradox - How Robots Are Making Work More Human. Oxford Economics. Available at: https://www.oxfordeconomics.com/recent-releases/the-AI-paradox

Lawrence, R. Ching, L.F., \& Abdullah, H. (2019), Strengths and Weaknesses of Education 4.0 in the Higher Education Institution. International Journal of Innovative Technology and Exploring Engineering, 9(2).

Liu, Q., Shi, X., Wang, X., \& Li, J. (2017). 5G Development in China: From Policy Strategy to User-Oriented Architecture. Mobile Information Systems, 2017, 1-11. doi:10.1155/2017/2358618

Marr, B. (2018). What is Industry 4.0? Here's A Super Easy Explanation For Anyone. Forbes. Retrieved from https://www.forbes.com/sites/bernardmarr/2018/09/02/what-is-industry-4-0-heres-a-super-easy-explanationfor-anyone/\#662cec59788a

Mikic, M. (2020). Industrial Revolution 4.0 and Inclusive Future of Work. ESCAP: Trade, Investment and Innovation Division.

Moore, M. (2019). What is Industry 4.0? Everything you need to know. TechRadar. Retrieved from https://www. techradar.com/news/what-is-industry-40-everything-you-need-to-know

Musa, S. F. P. D., \& Idris, D. S. R. P. H. (2020). Addressing Issues of Unemployment in Brunei: The Mismatch between Employers Expectations and Employees Aspirations. International Journal of Asian Business and Information Management, 11(2), 88-101. doi:10.4018/IJABIM.2020040106

Nardo, M. D., Forino, D., \& Murino, T. (2020). The evolution of man-machine interaction: The role of human in Industry 4.0 paradigm. Production \& Manufacturing Research, 8(1), 20-34. doi:10.1080/21693277.2020.1737592

Patil T. G., \& Shekhawat S. P. (2019). Industry 4.0 implications on Agriculture Sector: An Overview. Academic Press.

QS. (2020). Everything you need to know about education 4.0. Retrieved from https://www.qs.com/everythingyou-need-to-know-education-40/

Rose, D., \& Chilvers, J. (2018). Agriculture 4.0: Broadening Responsible Innovation in an Era of Smart Farming. Frontiers in Sustainable Food Systems, 2, 87. Advance online publication. doi:10.3389/fsufs.2018.00087

Rouse, M. (2017). Machine-to-machine (M2M). TechTarget. https://internetofthingsagenda.techtarget.com/ definition/machine-to-machine-M2M

Shepardson, D. (2020). Uber Self-Driving Cars with Humans in Control, to Cruise Washington, D.C. Friday. Reuters. Retrieved on March 22, 2020 from https://www.reuters.com/article/us-uber-self-driving/uber-selfdriving-cars-with-humans-in-control-to-cruise-washington-d-c-friday-idUSKBN1ZM2PH

Slusarczyk, B. (2018). Industry 4.0- Are We Ready? Polish. Journal of Management Studies, 17(1), 232-248.

Sujan, M., Furniss, D., Grundy, K., Grundy, H., Nelson, D., Elliott, M., White, S., Habli, I., \& Reynolds, N. (2019, November). Human Factors Challenges for the Safe Use of Artificial Intelligence in Patient Care. BMJ Health \& Care Informatics, 26(1), e100081. Advance online publication. doi:10.1136/bmjhci-2019-100081

Sumer, B. (2018). Impact of Industry 4.0 on Occupations and Employment in Turkey. European Scientific Journal, ESJ, 14(10), 1. doi:10.19044/esj.2018.v14n10p1

World Economic Forum. (2018). The Future of Jobs Report 2018. Academic Press. 
Zhuang, R., Fang, H., Zhang, Y., Lu, A., \& Huang, R. (2017). 'Smart Learning Environments for a Smart City: From the Perspective of Lifelong and Lifewide Learning'. Smart Learning Environments, 4(6), 1-21. doi:10.1186/s40561-017-0044-8

Ziegler, A., Debatin, T., \& Stoeger, H. (2019). Learning resources and talent development from a systemic point of view. Annals of the New York Academy of Sciences, 1445(1), 39-51. doi:10.1111/nyas.14018 PMID:30875101 